Ann. Biol. anim. Bioch. Biophys., I970, 10 (3), 4I3-430.

\title{
ACTION STIMULANTE DES MICROCOQUES CASEOLYTIQUES SUR LES BACTÉRIES LACTIQUES THERMOPHILES. MISE EN ÉVIDENCE DE LA NATURE PEPTIDIQUE DES SUBSTANCES STIMULANTES
}

\author{
M. DESMAZEAUD et J.-J. DEVOYOD \\ avec la collaboration technique de C. Auriault \\ Station centrale de Recherches laitières et de Technologie des Produits animaux, \\ Centre national de Recherches zootechniques, 78 -Jouy-en-Josas \\ Institut national de la Recherche agronomique
}

\section{RÉSUMÉ}

Parmi 306 souches de microcoques isolées à partir d'échantillons de lait prélevés stérilement à la mamelle, de lait de fromagerie, de lactosérum de fromagerie et de fromages à différents stades de la fabrication, 45 ont une action stimulante vis-à-vis des streptocoques thermophiles en culture dans le lait.

Ces microcoques ont un pouvoir caséolytique important. Les substances stimulantes produites par ces microcoques en culture dans le lait ont été séparées par filtration sur gel et identifiées comme étant des peptides.

Des protéolysats de caséine totale, de caséine $\alpha s_{1}$, de caséine $\beta$, de caséine $x$, de ribonucléase et de glucagon obtenus par action de la protéase neutre d'une souche de microcoque stimulant ont montré une action stimulante comparable à celle obtenue avec des filtrats de culture sur lait de microcoques caséolytiques. Cet effet stimulant est attribué à des peptides de poids moléculaire compris entre 1 ooo et I 500 .

\section{INTRODUCTION}

La plupart des fromages contiennent une flore microbienne comprenant, en proportion variable, des coques Gram-positifs, catalase-positifs, coagulase-négatifs que l'on désigne communément par le terme de "microcoques". Ces germes que l'on trouve habituellement dans le lait destiné à la fabrication du fromage proviennent soit de la mamelle, soit du matériel de traite et de fromagerie. On sait aussi que la microflore du lait pasteurisé est constituée en partie de microcoques ayant résisté au traitement thermique (THomas et al., I967). Toutes ces observations montrent qu'en technologie fromagère les levains lactiques se trouvent en présence de microcoques dans le lait de fabrication, que ce lait soit cru ou pasteurisé. Ces microcoques 
jouent-ils un rôle important, soit au cours de la fabrication, soit au cours de l'affinage du fromage? RITTER (I959 et I962) a constaté, par exemple, que les microcoques pouvaient avoir une action stimulante marquée vis-à-vis des lactobacilles utilisés comme levains dans la fabrication du Gruyère.

Dans le présent travail nous avons étudié un certain nombre de souches de microcoques isolées de la mamelle et des produits laitiers. Plusieurs de ces germes présentent une action stimulante marquée vis-à-vis des bactéries lactiques thermophiles, couramment utilisées comme levains en technologie. Nous avons recherché quelle était la nature des substances stimulantes produites par ces microcoques. Le fait que toutes les souches de microcoques stimulants étaient douées de propriétés protéolytiques importantes nous a conduit à comparer les substances stimulantes présentes dans les filtrats de culture sur lait de ces microcoques à celles obtenues par dégradation de la caséine totale et de différentes protéines par une protéase neutre isolée d'une souche de microcoque stimulant (DESMAzEAUd et HERMIER, Ig68 $a$ et $b$ ).

\section{MÉTHODES}

\section{Souches bactériennes}

\section{a) Microcoques.}

Trois cent six souches ont été utilisées dans ce travail. Leur origine est donnée dans le tableau I. Celles provenant de fromages ont été isolées à différents stades de la fabrication et de la maturation (Gruyère de Comté, Carré de l'Est, Saint-Paulin). Les techniques utilisées pour l'isolement et l'identification des microcoques ont été décrites antérieurement (DEvoYoD, I969).

\section{b) Bactéries lactiques thermophiles.}

Les souches des bactéries lactiques thermophiles utilisées dans cette étude étaient les sui. vantes (numéros de collection C. N. R. Z.) :

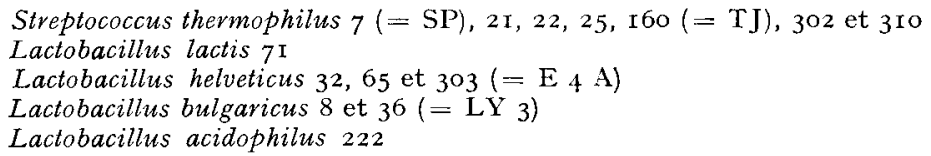

2. Mesure de l'activité stimulante des microcoques en culture associée avec les bactéries lactiques

Pour mesurer l'activité stimulante, on cultivait ensemble les bactéries lactiques et les microcoques et l'on comparait la production d'acide de ces cultures à celle des bactéries lactiques seules. Les cultures étaient faites sur lait reconstitué ( $100 \mathrm{~g}$ de poudre de lait écrémé Spray (Elle et Vire), instantanément soluble, exempte d'antibiotiques, pour I ooo $\mathrm{ml} \mathrm{d}$ d'eau distillée) chauffé à $90^{\circ} \mathrm{C}$ pendant zo minutes. Le lait était inoculé avec r p. Ioo d'une culture des bactéries lactiques sur lait de 16 heures à $37^{\circ} \mathrm{C}$ et avec I p. Ioo d'une culture de microcoques sur lait de I 6 heures à $30^{\circ} \mathrm{C}$. Après 4 heures d'incubation à $37^{\circ} \mathrm{C} \pm 0, \mathrm{I}^{\circ} \mathrm{C}$, on mesurait le $\mathrm{pH}$ des cultures à l'aide d'un $\mathrm{pH}$ mètre à électrode de verre ou l'on titrait leur aciclité par la soude N/ro.

Bien que $42^{\circ} \mathrm{C}$ soit la température optimum pour la mesure de l'activité des bactéries lactiques thermophiles, nous avons effectué les incubations des cultures associées à $37^{\circ} \mathrm{C}$ de façon à obtenir un meilleur développement des microcoques.

Nous avons également suivi l'acidification des cultures d'une manière continue à l'aide d'un pH-mètre enregistreur Metrohm. De plus, la croissance des microcoques a été suivie par dénom. 
brement sur milieu de CHAPMAN, celle des streptocoques thermophiles a été suivie par dénombrement sur milieu de Guss et Delwiche (1954) et celle des lactobacilles sur milieu M.R.S. (de MAN et al., I960).

\section{Mesure de l'activité stimulante des filtrats de culture des microcoques}

a) Obtention des filtrats de culture des microcoques.

\section{Cultures sur lait.}

Les cultures de microcoques sur lait autoclavé à I I $8^{\circ} \mathrm{C}$ pendant 20 minutes étaient incubées pendant 72 heures à $30^{\circ} \mathrm{C}$ puis filtrées sur filtre DuRIEux ${ }_{3} \mathrm{~B}$.

\section{Cultures sur lactosérum.}

A roo $\mathrm{ml}$ de lactosérum obtenu par coagulation par la présure du lait reconstitué chauffé à $90^{\circ} \mathrm{C}$ pendant 30 minutes et additionné de $\mathrm{CaCl}_{2}$ puis filtration stérilisante, on ajoutait $\mathrm{I} \mathrm{ml}$ d'une culture de 16 heures de microcoques sur lait. La durée d'incubation était de $7^{2}$ heures à $30^{\circ} \mathrm{C}$.

\section{Cultures sur milieu à la caséine.}

La caséine de vache préparée par précipitation à pH 4,6 par l'acide chlorhydrique N/Io selon la méthode d'HAMmarsten était mise en solution dans de l'eau et amenée à pH 7 par la soude $\mathrm{N} /$ Io. Le milieu de culture était composé de I p. Ioo de solution de caséine et o,5 p. Ioo de glucose. Il était stérilisé par filtration. A roo $\mathrm{ml}$ de milieu on ajoutait $\mathrm{I} \mathrm{ml}$ d'une culture de microcoques. La durée d'incubation était de 8 jours à $30^{\circ} \mathrm{C}$.

Les filtrats des cultures des microcoques sur lait, sur lactosérum et sur milieu à la caséine étaient stérilisés par filtration sur filtre Seitz EKS.

\section{b) Mesure de l'activité stimulante des filtrats de culture.}

Pour mesurer l'activité stimulante des filtrats de culture des microcoques, on cultivait les bactéries lactiques dans du lait additionné de I p. roo des différents filtrats; on comparait la production d'acide de ces cultures à celle des cultures de bactéries lactiques sur lait non additionné de filtrat. Après 4 heures d'incubation à $42^{\circ} \mathrm{C} \pm 0, I^{\circ} \mathrm{C}$, on mesurait le $\mathrm{pH}$ des cultures ou l'on titrait leur acidité, comme dans le cas des cultures associées.

\section{Séparation des substances stimulantes d'un filtrat de culture de microcoques sur lait et d'un protéolysat de caséine totale}

\section{a) Filtration sur gel.}

Nous avons utilisé indifféremment le Sephadex “medium grade, " préparé en $\mathrm{NaCl} 0,05 \mathrm{M}$ selon la technique décrite par PoRath (I959 et 1960), ou le Bio-Gel P6 (100-200 mesh) préparé en acide acétique $0,2 \mathrm{M}$. Par concentration sous vide à $42^{\circ} \mathrm{C}$ on réduisait de moitié le volume du filtrat de culture ou du protéolysat de caséine totale. Dix ml de filtrat de culture concentré ou $30 \mathrm{ml}$ du protéolysat concentré, étaient déposés au sommet de la colonne puis élués avec de l'acide acétique ( $\mathrm{M}$ dans le cas des colonnes de Sephadex et o,2 $M$ dans le cas des colonnes de Bio-Gel). Les fractions étaient recueillies au moyen d'un collecteur de fractions Seive ou G.M.E. et analysées par mesure de l'absorption à $280 \mathrm{~nm}$ au spectrophotomètre Beckman DU ou à l'Elugraph Seive et par coloration à la ninhydrine selon MoORE et STEıN sur o, I ml d'éluat. La quantité de tryptophane était appréciée de façon semi-quantitative par la méthode de FEIGL (I956), de façon quantitative par la méthode de BENCZE et SCHMID (I957). Les autres conditions sont décrites: dans la légende des figures 2 et 7 .

Les contenus des tubes correspondant à chaque pic d'absorption étaient réunis, desséchés sous vide à $4^{\circ} \mathrm{C}$, redissous dans l'eau distillée stérile et redesséchés sous vide à $42^{\circ} \mathrm{C}$, l'opération étant répétée 2 fois. A ce stade on a constaté que l'acide acétique était éliminé. Les résidus obtenus étaient conservés à $4^{\circ} \mathrm{C}$ jusqu'au moment où l'on mesurait l'activité stimulante.

\section{b) Mesure de l'activité stimulante.}

Les résidus correspondant aux pics d'absorption étaient dissous dans ro mI d'eau distillée stérile. Pour mesurer l'activité stimulante de ces solutions, on opérait de la même façon que dans le cas des filtrats de culture sur lait. 


\section{c) Technique bioautographique.}

Cette technique, décrite par SPEck et al., (I958), consiste d'abord à séparer les substances à etudier par chromatographie unidimensionnelle sur papier. Le chromatogramme obtenu est appliqué à la surface du milieu gélosé, contenant un indicateur coloré, ensemencé avec un organisme-test. Après incubation, les zones où l'organisme-test se développe (changement de couleur de l'indicateur) correspondent aux substances stimulantes séparées sur le chromatogramme.

Les résidus séchés correspondant aux pics d'absorption étaient dissous dans io ml d'eau distillée stérile. Pour chaque résidu, on disposait sur la ligne de base, sur une feuille de papier Whatman $\mathrm{n}^{\circ} 4$ de $46 \times 57 \mathrm{~cm}$, à des intervalles de 5 centimètres, des portions de 5 microlitres de cette préparation. Le solvant utilisé était le mélange Butanol - Acide acétique — Eau (4:1:5) $(\mathrm{v} / \mathrm{v})$. Après développement pendant I6 heures à la température ambiante, le front du solvant se trouvait à $4 \mathrm{~cm}$ environ du bas de la feuille. Les chromatogrammes étaient séchés puis découpés en bandes verticales. Les bandes marginales étaient révélées par pulvérisation du réactif à la ninhydrine de Moore et STEIn et chauffage à $100^{\circ} \mathrm{C}$ dans une étuve pendant I 5 minutes. Les bandes centrales étaient placées sous une sorbonne, à température ambiante, l'élimination du solvant étant réalisée par ventilation pendant 16 heures. Ce sont ces bandes qui servaient à rechercher les substances stimulantes par bioautographie.

Deux cent cinquante $\mathrm{ml}$ de gélose nutritive Plate Count Agar Difco no 479 additionnée d'un indicateur de $\mathrm{pH}$ (pourpre de bromocrésol à $0,02 \mathrm{p}$. I 00 concentration finale) étaient fondus, maintenus à $47^{\circ} \mathrm{C}$ puis ensemencés avec l'organisme-test (Streptococcus thermophilus 22 ou I60). Le milieu de culture inoculé était versé dans des boîtes en verre de $300 \times 190 \times 40 \mathrm{~mm}$. Après solidification du milieu, les bandes de chromatogramme étaient appliquées sur la gélose pendant Io à 15 minutes, puis étaient retirées. Les boîtes étaient alors mises à incuber à $37^{\circ} \mathrm{C}$ et examinées à intervalles réguliers pour déceler l'apparition des zones jaunes d'acidification.

\section{Préparation de la protéase neutre d'un microcoque activateur}

La protéase neutre utilisée pour l'obtention des différents protéolysats était obtenue à partir du surnageant de culture à $\mathrm{pH} 7,0$ de la souche de microcoque activateur $\mathrm{M} 96$ (DEsmazeaUd et Hermier, I968 a). La protéase était purifiée par précipitation au sulfate d'ammonium et par chromatographie sur D.E.A.E.-cellulose et sur Sephadex G. Ioo selon les techniques décrites précédemment (DESMAzEAUd et HERmier, I968 b). Cette protéase était obtenue en solution dans du tampon Tris-(hydroxyméthyle) aminométhane-maléate de sodium $0,005 \mathrm{M}$ à $\mathrm{pH} 7,0$ contenant du chlorure de calcium o, oor 5 M. La concentration en protéines était de $37 \mathrm{I} \mu \mathrm{g} / \mathrm{ml}$; son activité spécifique (unités $/ \mathrm{mg}$ de protéines) était de 2490 . Cette solution était conservée à $-30^{\circ} \mathrm{C}$ sans perte notable de son activité.

\section{Préparation des hydrolysats de protéines}

Afin de rechercher si les substances stimulantes produites par les microcoques étaient de nature peptidique, nous avons hydrolysé différentes caséines et protéines du lait par la protéase neutre de microcoque stimulant; les solutions peptidiques ainsi obtenues étaient essayées visà-vis des bactéries lactiques. D'autres protéines ont été également hydrolysées ; ces protéines de séquence connue (ribonucléase, lysozyme, insuline, glucagon) nous ont permis de confirmer la nature peptidique des substances stimulantes produites par les microcoques et de montrer l'importance éventuelle de la séquence en acides aminés des peptides stimulants.

\section{a) Préparation des solutions de protéines.}

La caséine totale, la $\beta$-lactoglobuline et l' $\alpha$-lactalbumine ont été obtenues chez Nutritional Biochemicals Corporation; la ribonucléase et le lysozyme chez Fluka; l'insuline et le glucagon chez Calbiochem. Les caséines $\alpha_{s 1} \mathrm{~B}, x \mathrm{~B}$ et $\beta \mathrm{B}$ ont été préparées par le Laboratoire de Recherches sur les Protéines (Station centrale de Recherches laitières, C. N. R. Z.).

Les protéines étaient mises en suspension dans l'eau distillée. La concentration finale était 2 p. гoo. Le pH était amené à 7,5 par addition de soude $\mathrm{N}$.

\section{b) Conditions d'hydrolyse.}

A $100 \mathrm{ml}$ de solution de caséine totale on ajoutait $\mathrm{I} \mathrm{ml}$ de la solution de la protéase neutre. L'hydrolyse était effectuée à $30^{\circ} \mathrm{C}$. Le $\mathrm{pH}$ était maintenu entre 7,45 et 7,55 par addition de soude N/Io. L'hydrolyse était suivie par mesure de l'absorption à $275 \mathrm{~nm}$ du filtrat après précipitation du mélange réactionnel par l'acide trichloracétique à 6 p. Ioo (KUNITZ, I947). 
A Io $\mathrm{ml}$ des solutions de caséine $\alpha_{s_{1}} \mathrm{~B}, \chi \mathrm{B}, \beta \mathrm{B}$, de $\beta$-lactoglobuline, d' $\alpha$-lactalbumine, d'insuline, de ribonucléase et de lysozyme on ajoutait $o, \mathrm{I} \mathrm{ml}$ de protéase neutre. L'hydrolyse était effectuée dans les mêmes conditions que ci-dessus, mais elle était suivie par mesure de la coloration à la ninhydrine de o, I ml du mélange réactionnel (MOORE et STEIN, I954).

A $\mathrm{r} \mathrm{ml}$ de la solution de glucagon on ajoutait to microlitres de protéase neutre. L'hydrolyse était effectuée et contrôlée par le réactif à la ninhydrine dans les mêmes conditions que ci-dessus.

c) Préparation des protéolysats.

Protéolysat de caséine totale.

$\mathrm{Au}$ bout de différents temps d'incubation on prélevait $9 \mathrm{ml} \mathrm{du}$ mélange réactionnel auxquels on ajoutait goutte à goutte $\mathrm{I} \mathrm{ml}$ d'acide acétique $2 \mathrm{~N}$ afin d'inactiver la protéase et de précipiter les molécules de caséine non hydrolysées. Après 4 heures de contact à température ambiante, le précipité était éliminé par centrifugation à $30000 \mathrm{~g}$ pendant 20 minutes. Les surnageants étaient desséchés sous vide à $42^{\circ} \mathrm{C}$.

Protéolysat des protéines autres que la caséine totale.

A l'hydrolyse maximum, les enzymes étaient inactivés par chauffage du mélange réactionnel à $100^{\circ} \mathrm{C}$ pendant 5 minutes. Celui-ci était refroidi et son $\mathrm{pH}$ était amené à 6,5 . Ces solutions étaient conservées à $-30^{\circ} \mathrm{C}$ jusqu'à leur utilisation.

d) Mesure de l'activité stimulante des protéolysats.

Pour mesurer l'activité stimulante des protéolysats, on opérait de la même façon que dans le cas des filtrats de culture de microcoques sur lait.

\section{RÉSULTATS}

\section{Microcoques stimulants - Bactéries lactiques stimulées}

On considérait que les souches de microcoques essayées étaient stimulantes lorsqu'en association avec les bactéries lactiques, le $\mathrm{pH}$ des cultures était inférieur d'au moins 0,5 unité à celui des cultures de bactéries lactiques seules. Dans le cas où le $\mathrm{pH}$ des cultures associées était supérieur d'au moins 0,5 unité au $\mathrm{pH}$ des cultures de bactéries lactiques, les souches de microcoques étaient considérées comme inhibitrices. Dans les conditions expérimentales utilisées, les microcoques ne modifiaient pas le $\mathrm{pH}$ du lait.

Parmi les bactéries lactiques essayées, seules les souches de Str. thermophilus se sont montrées sensibles à l'action stimulante ou inhibitrice des microcoques, les lactobacilles n'étant ni stimulés, ni inhibés.

Sur les 306 souches de microcoques, 45 (soit I5 p. Ioo) avaient une action stimulante, 20 (soit 7 p. IOo) avaient une action inhibitrice et $24 \mathrm{I}$ ne présentaient aucune action, stimulante ou inhibitrice. Le tableau I donne la répartition des souches stimulantes et inhibitrices de microcoques suivant leur origine. Les microcoques stimulants provenant des fromages avaient été isolés à partir d'échantillons prélevés au cours des premiers stades de la fabrication.

Toutes les souches stimulantes manifestaient une forte activité caséolytique : les colonies obtenues sur lait gélosé étaient entourées d'une zone claire de I cm de diamètre environ, qui apparaissait après 36 à 48 heures d'incubation. La croissance de ces souches était faible à $\mathrm{pH}_{5}$ et aucune multiplication ne se produisait à $\mathrm{pH} 4$. Cependant toutes les souches caséolytiques n'étaient pas stimulantes. Nous avons en effet isolé dans des fromages en fin d'affinage des microcoques dont l'action sur la 
caséine était différente de celle que nous venons d'indiquer : sur lait gélosé, la zone de clarification autour des colonies était toujours petite et ils ne peptonisaient pas le lait. Ces microcoques n'avaient aucune action stimulante vis-à-vis des streptocoques lactiques thermophiles.

\section{TABLEAU I}

Répartition des souches de microcoques stimulantes et inhibitrices, suivant leur origine

\begin{tabular}{|c|c|c|c|c|}
\hline \multirow[b]{2}{*}{ Origine } & \multirow{2}{*}{$\begin{array}{c}\text { Nombie de } \\
\text { souches } \\
\text { essayées }\end{array}$} & \multirow{2}{*}{$\begin{array}{l}\text { Nombre de } \\
\text { souches } \\
\text { inhibitrices }\end{array}$} & \multicolumn{2}{|c|}{ Souches stimulantes } \\
\hline & & & Nombre & $\begin{array}{l}\% \text { de souches } \\
\text { essayćes }\end{array}$ \\
\hline $\begin{array}{l}\text { Lait prélevé stérilement à la } \\
\text { mamelle } \ldots \ldots \ldots \ldots \ldots \ldots \ldots\end{array}$ & 88 & 1 & 13 & 147 \\
\hline Lait de fromagerie $\ldots \ldots \ldots \ldots$ & 99 & 0 & 21 & 21 \\
\hline Lactosérum $\ldots \ldots \ldots \ldots \ldots$ & $5^{\prime}$ & 0 & 4 & $7, \mathbf{i}$ \\
\hline Caillé à la mise en moules & 35 & 2 & 7 & 20 \\
\hline Fromage en cours d'affinage & 30 & 17 & 0 & 0 \\
\hline 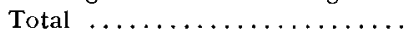 & 306 & 20 & 45 & 14,7 \\
\hline
\end{tabular}
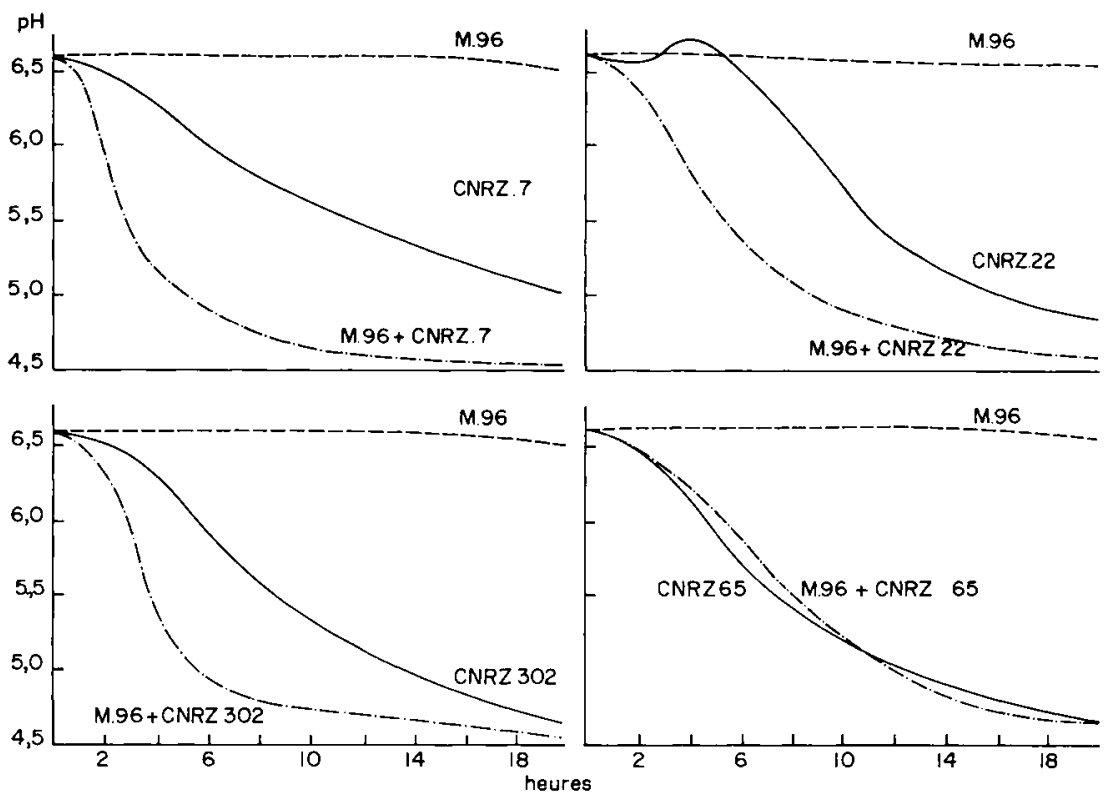

FIc. I. - Action d'une souche de microcoques casếlytiques sur l'activitê des bactéries lactiques thermophiles

Variations du pH en fonction du temps. Inoculum : I p. Ioo Température d'incubation : $37^{\circ} \mathrm{C}$. C. N. R.Z. 7, 22 et 302 : Streptococcus thermophilus C.N.R.Z. 65 : Lactobacillus helveticus M. 96 : Microcoque caséolytique.

Pour étudier d'une façon plus précise l'action des microcoques sur la production d'acide des bactéries lactiques thermophiles, nous avons suivi l'évolution du pH des cultures associées. Le travail a été réalisé avec Iz souches de microcoques. La figure I 
montre, à titre d'exemple, les variations de $\mathrm{pH}$ observées dans des cultures associées de la souche de microcoque caséolytique M 96 et des souches de Str. thermophilus 7 , 22 et 302 et de Lactobacillus helveticus 65 . On voit que pour les cultures associées de Str. thermophilus et de microcoques la production d'acide est nettement plus rapide que pour les cultures de streptocoques seuls; on constate de plus que la quantité maximum d'acide produite reste plus importante dans le cas des cultures associées. On remarque dans le cas de Str. thermophilus 22 cultivé seul, une légère remontée du $\mathrm{pH}$ au début de la culture; ce phénomène, non expliqué, est habituel chez cette souche.

Par contre, on voit qu'aucune action, stimulante ou inhibitrice, ne se manifeste dans les cultures associées de $L$. helveticus et de microcoques. Pour les autres souches de microcoques essayées, les courbes obtenues montraient les mêmes caractéristiques.

Compte tenu de la précision des résultats des numérations, on ne peut affirmer si l'augmentation de l'acidité constatée dans le cas des streptocoques thermophiles est due à une augmentation du nombre de ces microorganismes ou à une stimulation de la production d'acide.

\section{Action stimulante des filtrats de culture de microcoques}

Le tableau 2 montre les résultats obtenus en ajoutant à du lait, chauffé à $90^{\circ} \mathrm{C}$ pendant 30 minutes, I p. Ioo des différents filtrats de culture de la souche de micro-

TABLEAU 2

Action des filtrats de culture de la souche de microcoque caséolytique $M 96$ vis-à-vis de trois souches de Streptococcus thermophilus

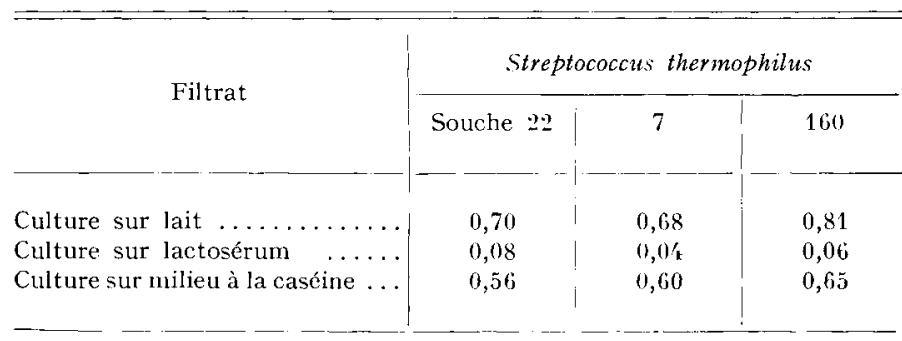

Les valeurs données correspondent à la différence entre le $\mathrm{pH}$ des cultures des streptocoques thermophiles seuls et le $\mathrm{pH}$ des cultures ayant reçu 1 p. 100 de filtrat.

Inoculum : 1 p. 100 d'une culture sur lait de 16 heures à $37^{\circ} \mathrm{C}$.

Incubation : 4 heures à $42^{\circ} \mathrm{C}$.

coque M 96 (filtrats de culture sur lait, sur lactosérum et sur milieu à la caséine). On voit que seuls les filtrats de culture sur lait et sur milieu à la caséine présentent une action stimulante vis-à-vis des streptocoques thermophiles.

\section{Caractérisation des substances stimulantes produites par les microcoques}

On a caractérisé les substances stimulantes présentes dans un filtrat de culture sur lait de la souche de microcoque $\mathrm{M} 96$. Ce filtrat de culture a été chromatographié sur Sephadex G-25. 
La figure 2 montre la courbe d'élution de ce filtrat de culture. On observe 6 pics d'absorption. Le pic $P_{1}$, qui apparaît aussitôt après le passage du volume mort de la colonne, correspond aux protéines et peptides de poids moléculaire supérieur à 5 ooo. Les pics stuccessifs correspondent à des substances de poids moléculaires de moins en moins élevés. Quant aux pics $P_{5}$ et $P_{6}$, dont le volume d'élution est supérieur au volume total de la colonne, nous avons vérifié qu'ils contenaient bien des peptides riches en acides aminés aromatiques, ce qui explique leur retard d'élution.

Les différentes fractions correspondant à chaque pic d'absorption ont été réunies et nous avons recherché dans quel pic se trouvaient les substances stimulantes. On voit dans le tableau 3 que les fractions correspondant au pic $\mathrm{P}_{3}$ ont une action stimulante marquée vis-à-vis des streptocoques thermophiles. Ce pic $\mathrm{P}_{3}$ correspond à la zone d'élution des substances de poids moléculaire compris entre I ooo et I 500 .

Bien que les autres pics semblent montrer une légère stimulation, nous nous sommes limités à l'étude du pic $\mathrm{P}_{3}$ qui donnait la plus forte stimulation.

Le produit obtenu par dessiccation des fractions rassemblées, correspondant au pic $P_{3}$, était insoluble dans le chloroforme, l'acétone et l'éthanol absolu ; il était soluble dans $\mathrm{HCl} \mathrm{N} /$ IO et $\mathrm{NH}_{4} \mathrm{OH} \mathrm{N} /$ IO. Il donnait une réaction positive avec la ninhydrine. Les substances contenues dans les fractions correspondant au pic $P_{3}$ sont donc vraisemblablement de nature peptidique.

La figure 3 montre un chromatogramme sur papier du pic $P_{3}$. Les fractions correspondant à ce pic contiennent au moins ro substances distinctes réagissant avec la ninhydrine. Par bioautographie nous avons mis en évidence 4 substances stimulantes coïncidant avec 4 taches ninhydrine-positives (taches hachurées sur le chromatogramme de la figure 3 ). Les substances stimulantes contenues dans les fractions correspondant au pic $P_{3}$ sont donc des peptides.

\section{Action stimulante d'un hydrolysat enzymatique de caséine totale}

Nous avons étudié l'action stimulante de l'hydrolysat de caséine totale par la protéase neutre de Micrococcus caseolyticus M 96. Comme dans le cas des filtrats de culture, parmi les différentes bactéries lactiques thermophiles essayées, seules les souches de Str. thermophilus étaient stimulées. La figure 4 montre, à titre d'exemple, les variations de $\mathrm{pH}$ des cultures de Str. thermophilus 25 et de $L$. helveticus 303 sur lait avec et sans addition de ce protéolysat correspondant à l'hydrolyse maximum. La culture de Str. thermophilus supplémentée présente après 2 heures de culture une chute du $\mathrm{pH}$ plus rapide que la culture de Str. thermophilus seul. La culture supplémentée atteint un $\mathrm{pH}$ de 5,5 au bout de 3 heures alors que la valeur du $\mathrm{pH}$ de la culture témoin est de 6,I. Pendant toute l'incubation le pH de la culture supplémentée est plus bas. Au bout de I5 heures, la différence est encore de 0,4 unité $\mathrm{pH}$. Par contre, il n'y a aucun effet stimulant sur $L$. helveticus, les valeurs de $\mathrm{pH}$ des cultures supplémentées étant égales à celles de la culture témoin.

Comme le montre le tableau 4, toutes les souches de Str. thermophilus essayées sont activées par 1'hydrolysat enzymatique de caséine totale. En effet la quantité d'acide produite par les cultures supplémentées en protéolysat de caséine totale correspondant à 1'hydrolyse maximum est toujours supérieure à la quantité d'acide produite par les cultures de Str. thermophilus seules.

On a cherché à voir quelle était l'influence du temps d'hydrolyse de la caséine 


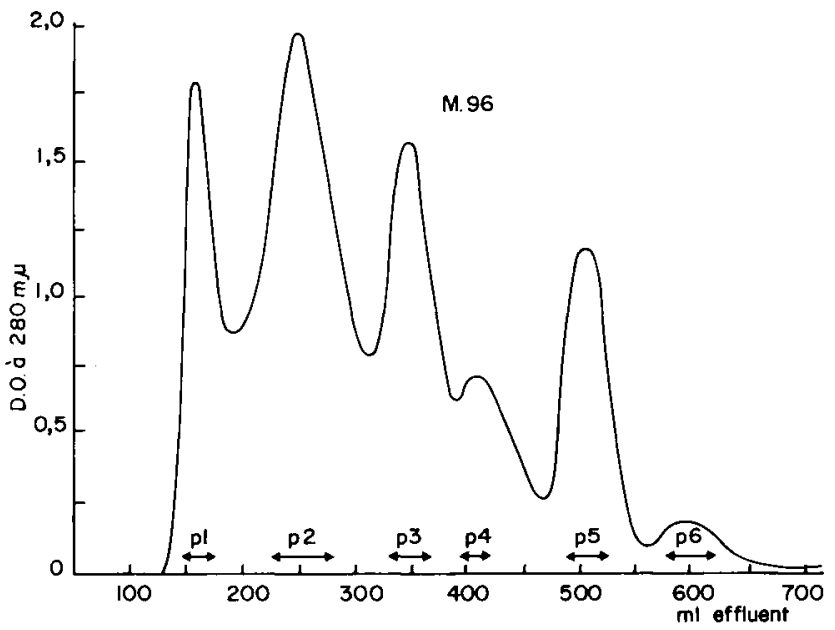

FIG. 2. - Fractionnement sur Sephadex $G 25$ d'un filtrat de culture sur lait de la souche $M 96$ de microcoques caséolytiques

Courbe d'élution mesurée par la densité optique à $280 \mathrm{~nm}$. Vitesse d'élution $50 \mathrm{ml} / \mathrm{heure.} \mathrm{Éluant} \mathrm{:}$ acide acétique $\mathrm{M}(\mathrm{pH}: 2,5)$. Volume des fractions : $5 \mathrm{ml}$. Colonne : $35 \mathrm{~mm}$ de diamètre; $\mathrm{I}$ ooo $\mathrm{mm}$ de hauteur.

\section{TABLEAU 3}

Action stimulante, vis-à-vis des streptocoques thermophiles, des fractions correspondant aux différents pics d'absorption d'un filtrat de culture sur lait de la souche de microcoque $M 96$. Chromatographie sur Sephadex $G 25$

\begin{tabular}{c|c|c|c}
\hline \hline $\begin{array}{c}\text { Pics d'absorption } \\
\text { (Cf. fig. 2) }\end{array}$ & \multicolumn{3}{|c}{ Streptococcus thermophilus } \\
\cline { 2 - 3 } & Souche 22 & 7 & 160 \\
& & & \\
\hline$P_{1}$ & 0,05 & 0,10 & 0,06 \\
$P_{2}$ & 0,12 & 0,13 & 0,10 \\
$P_{3}$ & 0,60 & 0,71 & 0,68 \\
$P_{4}$ & 0,17 & 0,19 & 0,12 \\
$P_{5}$ & 0,10 & 0,12 & 0,10 \\
$P_{6}$ & 0,18 & 0,15 & 0,19 \\
\end{tabular}

Les valeurs données correspondent à la différence entre le pH des cultures des streptocoques thermophiles seuls et le $\mathrm{pH}$ des cultures ayant reçu 1 p. 100 des differentes fractions.

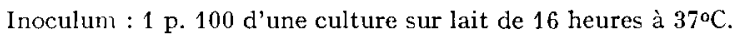

Incubation : 4 heures à $42^{\circ} \mathrm{C}$. 


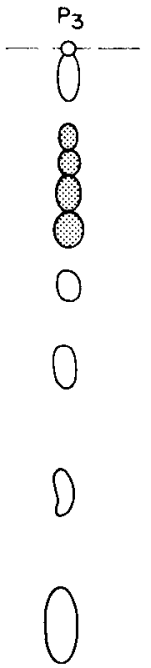

Front du solvant

FIG. 3. - Chromatogramme sur papier du pic stimulant $P$ 3 de fultrat de culture sur lait de $M 96$

Papier Whatman $n^{\circ} 4$. Solvant Butanol-Acide acétique-Eau $(4: 1: 5)(v / v)$

Taches révélées par pulvérisation du réactif à la ninhydrine de MoORE et STEiN.

En grisé : les zones qui correspondent à l'activité stimulante.
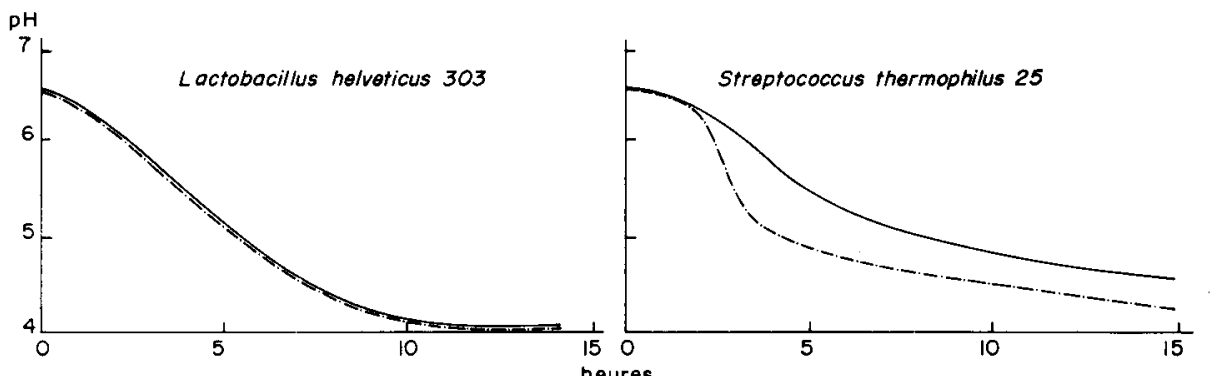

FIG. 4. - Action de l'hydrolysat enzymatique de caséine totale par la protéase neutre du microcoque stimulant $M 96$, sur l'activité des bactéries lactiques

Variations du pH en fonction du temps. Inoculum I p. roo d'une culture de 16 heures à $37^{\circ} \mathrm{C}$. Les cultures supplémentées ont reçu I p. Ioo de l'hydrolysat enzymatique de caséine totale. Température d'incubation : $42^{\circ} \mathrm{C}$.

: cultures témoins.

$\cdot-\cdots \cdot-$ : cultures supplémentées. 
TABLEAU 4

Influence sur différentes souches de Str. thermophilus du protéolysat de caséine totale correspondant à l'hydrolyse maximum

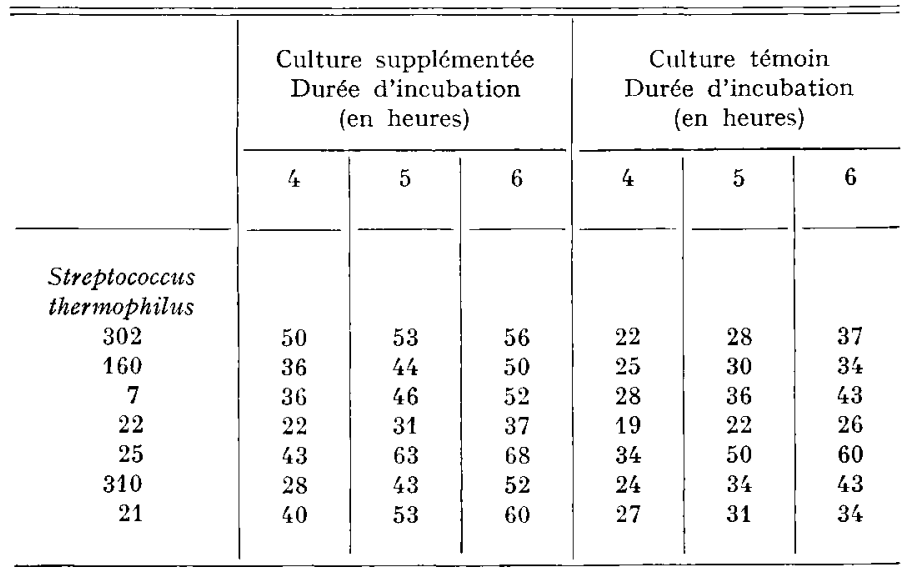

Acidité exprimée en degrés Dornic.

Incubation à $42^{\circ} \mathrm{C}$.

Inoculum : 1 p. 100 d'une culture sur lait de 16 heures à $37^{\circ} \mathrm{C}$.

Les cultures supplémentées ont reşu 1 p. 100 du protéolysat.

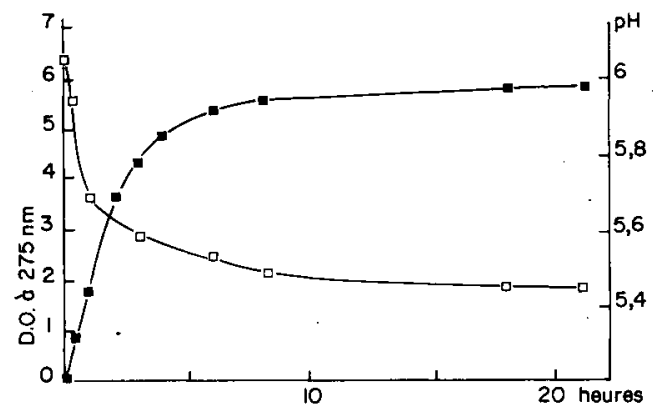

FIG. 5. - Relation entre la durée de l'hydrolyse enzymatique de la caséine totale par la protéase neutre du microcoque stimulant $M 96$ et l'activité de Streptococcus thermophilus 160.

Inoculum : I p. roo d'une culture de i 6 heures à $37^{\circ} \mathrm{C}$.

les cultures sont supplémentées avec I p. Ioo des protéolysats correspondant aux différents temps J'hydrolyse.

Le pH des cultures est mesuré après 5 heures d'incubation à $42^{\circ} \mathrm{C}$.

La protéolyse est estimée par la variation de la densité optique à $275 \mathrm{~nm}$ du filtrat trichloracétique. $\square-\square \mathrm{pH}$ de la culture sur lait après 5 heures.

n-m densité optique à $275 \mathrm{~nm}$ du filtrat trichloracétique. 
totale sur la production de substances stimulantes. La figure 5 montre que la production d'acide de Str. thermophilus r6o est de plus en plus importante lorsqu'on ajoute à la culture des protéolysats provenant d'hydrolyses de plus en plus prolongées. On voit que l'action stimulante maximum est obtenue pour l'hydrolyse maximum.

La figure 6 montre l'influence de la concentration en protéolysat, correspondant à l'hydrolyse maximum, sur la production d'acide des 2 souches de Str. thermophilus

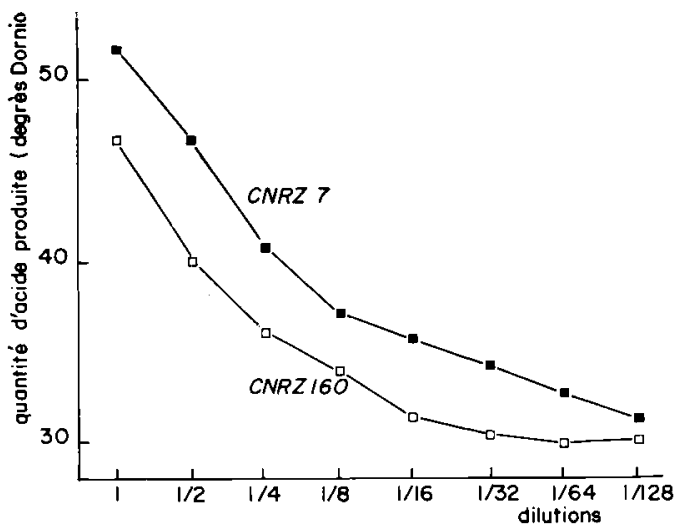

F1G. 6. - Influence de la concentration en hydrolysat enzymatique de la caséine totale par la protéase neutre du microcoque stimulant $M 96$ sur l'activité des streptocoques thermophiles

Inoculum : I p. Ioo d'une culture de I 6 heures à $37^{\circ} \mathrm{C}$.

Les cultures sont supplémentées avec I p. Ioo des différentes dilutions du protéolysat de caséine totale correspondant à l'hydrolyse maximum.

La quantité d'acide produite est exprimée en degrés Dornic.

L'incubation est effectuée à $42^{\circ} \mathrm{C}$ pendant 5 heures.

7 et $\mathbf{1 6 0}$. Même à la concentration maximum employée, correspondant à $0,4 \mathrm{mg}$ de protéolysat de caséine totale par $\mathrm{ml}$ de lait ensemencé, on n'atteint pas la stimulation maximum; en effet, on ne constate pas de phénomène de seuil. On voit que la souche de Str. thermophilus 7 est très sensible au phénomène d'activation, puisque celui-ci est encore décelable à une dilution de I/64.

\section{Fractionnement des peptides stimulants}

La figure 7 montre les courbes d'élution obtenues à partir du protéolysat de caséine totale correspondant à l'hydrolyse maximum, après chromatographie sur gel. Comme pour le filtrat de culture sur lait du microcoque $M 96$ chromatographié sur gel, le pic $p_{1}$, qui apparaît aussitôt après le passage du volume mort de la colonne, correspond aux protéines et peptides de poids moléculaire supérieur à 5 ooo. Le pic $\mathrm{p}_{3}$ correspond à la zone d'élution des substances de poids moléculaire compris entre I 000 et I 500. Le pic $\mathrm{p}_{4}$ correspond à la zone d'élution des peptides courts ou des acides aminés. Quand aux pics $p_{5}$ et $p_{6}$ dont le volume d'élution est supérieur au volume total de la colonne, ils contiennent des peptides riches en acides aminés aromatiques. Si l'on compare la courbe d'élution des filtrats de culture sur lait du microcoque M 96 d'une part et celle de l'hydrolysat enzymatique de caséine totale par la protéase neutre de ce microcoque, on constate une différence importante entre les hauteurs relatives des pics correspondants dans les deux courbes. Dans le cas du 


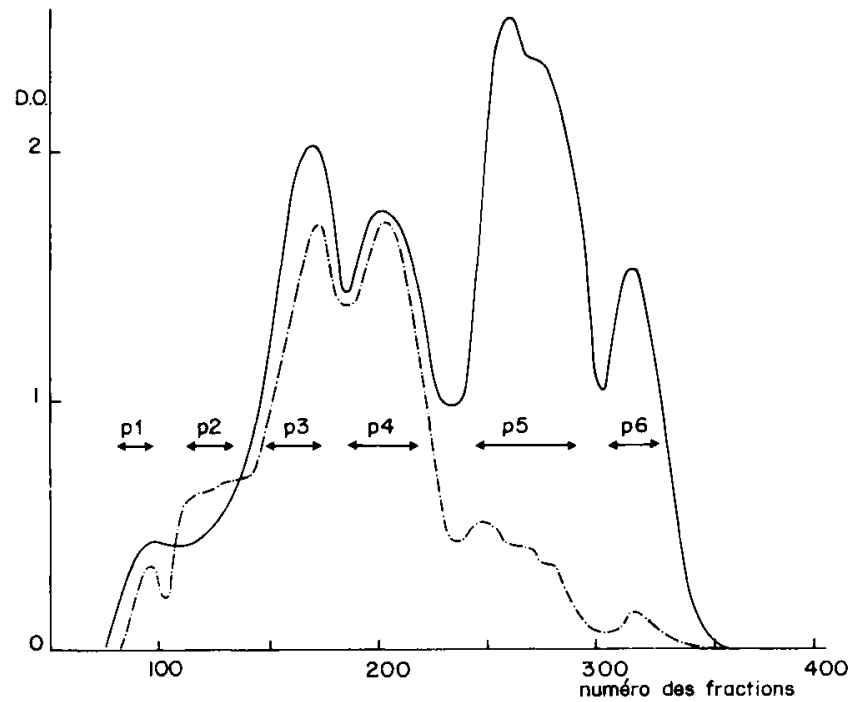

FIG. 7. - Fractionnement sur Bio-Gel $P 6$ d'un hydrolysat enzymatique de caséine totale par la protéase neutre du microcoque stimulant $M 96$

Courbes d'élution mesurées par l'absorption en ultra-violet à $280 \mathrm{~nm}$ et à $570 \mathrm{~nm}$ après coloration par le réactif à la ninhydrine de o, I $\mathrm{ml}$ d'éluat.

Vitesse d'élution environ $70 \mathrm{ml} /$ heure.

Éluant : acide acétique $0,2 \mathrm{M}$. Volume des fractions : Io ml. Colonne : $45 \mathrm{~mm}$ de diamètre ; $1450 \mathrm{~mm}$ de hauteur.

courbe d'élution à $280 \mathrm{~nm}$.

\section{TABLEAU 5}

Action stimulante, vis-à-vis de Streptococcus thermophilus 160 , des fractions correspondant aux différents pics d'absorption d'un protéolysat de caséine totale par la protéase neutre de Micrococcus caseolyticus $M 96$ après chromatographie sur Bio-Gel $P 6$

\begin{tabular}{|c|c|c|c|c|c|c|c|c|}
\hline & \multirow[b]{2}{*}{$\begin{array}{l}\text { Culture } \\
\text { témoin }\end{array}$} & \multicolumn{7}{|c|}{$\begin{array}{l}\text { Cultures supplémentées avec les fractions } \\
\text { correspondant aux pirs numérotés }\end{array}$} \\
\hline & & $\begin{array}{c}\text { en hydro- } \\
\text { lysat } \\
\text { total }\end{array}$ & 1 & 2 & 3 & 4 & 5 & 6 \\
\hline $\begin{array}{l}\text { Acidité après } 4 \text { k } h \mid \\
\text { de culture } \ldots . . .\end{array}$ & 20 & 37 & 19,5 & 21 & 35,5 & 21,5 & 18,5 & 21 \\
\hline $\begin{array}{c}\text { Acidité après } 5 \quad h \\
\text { de culture } \ldots . .\end{array}$ & 27 & 51 & 21 & $3^{\prime}$ & 52,5 & 30 & 25,5 & 25 \\
\hline
\end{tabular}

L'acidité est exprimée en degrés Dornic.

L'incubation est effectuée à $42^{\circ} \mathrm{C}$.

Inoculum : 1 p. 100 d'une culture sur lait de 16 heures à $37^{\circ} \mathrm{C}$.

Les cultures supplémentées ont reçu 1 p. 100 des différentes fractions. 
protéolysat de caséine totale, les pics contenant les substances de haut poids moléculaire sont plus petits que dans les filtrats de culture sur lait. Ceci indique une hydrolyse plus poussée dans le cas du protéolysat de caséine totale que dans celui des filtrats de culture.

Comme pour le filtrat de culture sur lait, le tableau 5 montre que seules les fractions correspondant au pic $\mathrm{p}_{3}$ présentaient une action très stimulante vis-à-vis de Str. thermophilus 160 . Les fractions correspondant aux pics $p_{2}$ et $p_{1}$ ne présentaient qu'une faible action stimulante, tandis que celles correspondant aux pics $p_{1}, p_{5}$ et $p_{6}$ présentaient une action faiblement inhibitrice. C'est pourquoi, dans le cas des filtrats de culture sur lait la faible action stimulante constatée pour les pics $P_{1}, P_{5}$, $P_{6}$, (figure 2) est due sans doute à des substances autres que les peptides de la caséine.

De plus, les chromatographies sur gel des protéolysats de caséine totale correspondant aux différents temps d'hydrolyse, montraient aussi que la stimulation était maximale lorsque le pic $p_{3}$ atteignait aussi sa taille maximale.

\section{Action stimulante des hydrolysats enzymatiques de protéines autres que la caséine totale}

Dans le tableau 6 nous avons porté les différences de densité optique à 570 m $\mu$ (après coloration à la ninhydrine) entre les solutions non hydrolysées des protéines du lait et les solutions correspondant à l'hydrolyse maximale. On constate que les protéines du sérum sont plus faiblement hydrolysées que les caséines.

Le tableau 7 donne à titre de comparaison l'acidité produite par des cultures

TABLEAU 6

Activité protéolytique, sur les différentes protéines du lait, de la protéase neutre de Micrococcus caseolyticus $M 96$

\begin{tabular}{|c|c|}
\hline & $\begin{array}{c}\text { Variation de la densité optique } \\
\text { à } 570 \mathrm{~m} \mu\end{array}$ \\
\hline Caséine totale $\ldots \ldots \ldots \ldots \ldots \ldots$ & 1,90 \\
\hline Caséine $\alpha_{s_{1}} \mathrm{~B} \ldots \ldots \ldots \ldots$ & 1,70 \\
\hline Caséine $\beta B \ldots \ldots \ldots \ldots \ldots$ & 1,45 \\
\hline Caséine $\varkappa B \ldots \ldots \ldots \ldots \ldots \ldots$ & 1,22 \\
\hline$\alpha$-lactalbumine $\ldots \ldots \ldots \ldots \ldots \ldots$ & $(0,32$ \\
\hline$\beta$-lactoglobuline $\ldots \ldots \ldots \ldots \ldots \ldots$ & 0,75 \\
\hline
\end{tabular}

Les valeurs données correspondent à la différence entre la densité optique à $570 \mathrm{~m} \mu$ des solutions non hydrolysées et des solutions correspondant à l'hydrolyse maximale, après coloration par le réactif à la ninhydrine.

I a coloration était effectuée par $1 \mathrm{ml}$ du réactif à la ninhydrine sur $0,1 \mathrm{ml}$ du mélange réactionnel dilué dans $0,9 \mathrm{ml}$ d'eau distillée.

Après 15 minutes au bain-marie bouillant, puis refroidissement, on ajoutait $8 \mathrm{ml}$ d'alcool à 50 p. 100 .

de Str. thermophilus r6o sur lait, après addition des différents protéolysats. Afin de pouvoir comparer leur action stimulante, les différents protéolysats employés correspondaient tous à l'hydrolyse maximale obtenue. 
Les hydrolysats de caséine $\alpha_{s 1} B$ et de caséine $x B$ présentaient l'effet activateur le plus marqué bien que plus faible que celui de la caséine totale. Les hydrolysats de caséine $\beta B$, de ribonucléase et de lysozyme présentaient un effet stimulant plus faible que celui de la caséine $\alpha_{s 1} B$. Par contre, les hydrolysats d'insuline, de $\beta$-lactoglobuline et d' $\alpha$-lactalbumine ne présentaient aucun effet stimulant. Quant au glu-

TABLEAU 7

Infuence des protéolysats sur l'acidification des cultures sur lait de Str. thermophilus 160

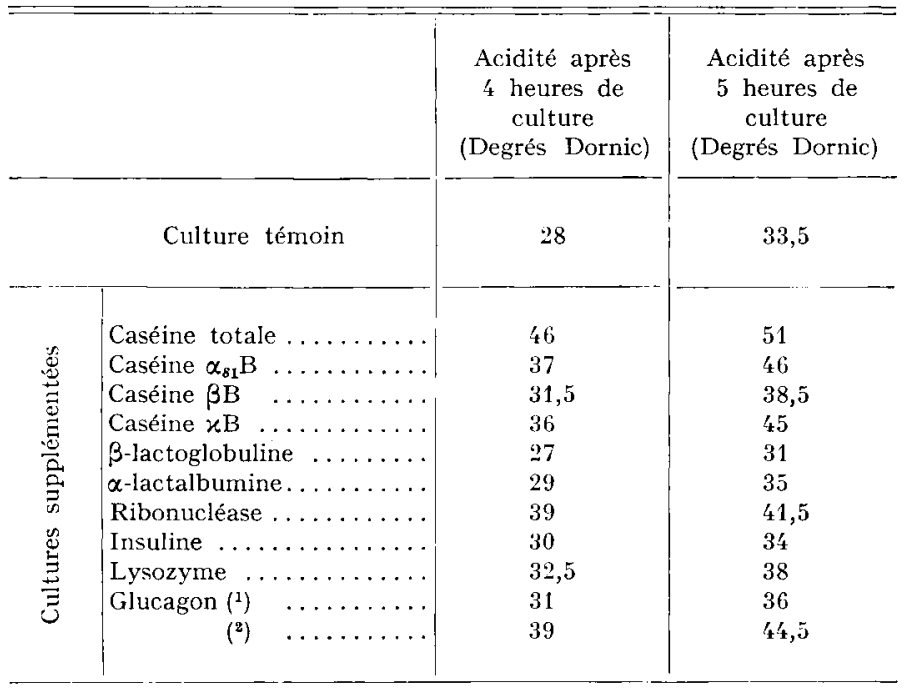

(1) Non hydrolysé.

(2) Après hydrolyse.

L'acidité est exprimée en degrés Dornic.

Inoculum : 1 p. 100 d'une culture sur lait de 16 heures à $37^{\circ} \mathrm{C}$.

Incubation à to

Les cultures supplémentées ont reçu 1 p. 100 des différents protéolysats.

cagon hydrolysé, il présentait un pouvoir activateur marqué, inférieur cependant à celui de l'hydrolysat de caséine $\alpha_{s 1} B$. Il faut cependant noter que le glucagon non hydrolysé présentait un léger pouvoir stimulant.

\section{DISCUSSION}

Lorsque l'acidité du caillé augmente, les microcoques caséolytiques stimulants disparaissent; c'est pourquoi nous ne les trouvons qu'au cours des premiers stades de la fabrication. En effet à $\mathrm{pH} 5$ ces microcoques ne se multiplient pas et à $\mathrm{pH} 4,5$ leur nombre diminue rapidement. Le fait que nous n'ayons pas trouvé de souches stimulantes ni dans l'atmosphère des étables ni dans la flore du matériel de traite 
(DEvoyod, résultats non publiés) semble indiquer qu'une partie importante de ces microcoques stimulants est d'origine mammaire.

Il semble bien que l'intensité du pouvoir caséolytique des souches de microcoques soit en relation directe avec leur action stimulante. Fin effet nos résultats ont montré que les microcoques qui avaient une action stimulante vis-à-vis des streptocoques lactiques thermophiles avaient un pouvoir caséolytique élevé, tandis que les microcoques moins caséolytiques que nous avons isolés d'échantillons de fromages prélevés en fin d'affinage ne stimulaient pas les streptocoques lactiques thermophiles. Nos résultats sont à rapprocher de ceux de PEPPLER (I942) qui a montré que Str. thermophilus était activé par des espèces bactériennes très fortement protéolytiques telles que Str. liquefaciens, Pseudomonas aeruginosa et Proteus ammoniae.

Par contre, nos résultats semblent être en contradiction avec ceux de RITTER (I962) qui observait une activation des lactobacilles et non des streptocoques thermophiles par des souches de microcoques. Il faut toutefois remarquer que les souches utilisées par cet auteur n'appartenaient pas à des espèces fortement caséolytiques. On peut donc penser que l'activation des lactobacilles ne se fait vraisemblablement pas par la même voie métabolique que dans le cas des streptocoques thermophiles.

Nos résultats ont montré que les cultures sur lait des microcoques caséolytiques, comme l'hydrolysat de caséine totale par la protéase neutre d'un microcoque, contenaient des peptides stimulants de poids moléculaire compris entre I 500 et I ooo. Nos résultats ont montré aussi que les cultures sur lactosérum des microcoques caséolytiques, comme les hydrolysats enzymatiques de $\beta$-lactoglobuline et d' $\alpha$-lactalbumine, ne contenaient pas de substances stimulantes. On peut donc affirmer que la stimulation dans le lait des streptocoques thermophiles par les microcoques caséolytiques est bien due à des peptides provenant de la dégradation des caséines.

Cette action stimulante des peptides de caséine vis-à-vis de Streptococcus thermophilus est en accord avec celle déjà observée chez d'autres bactéries, en particulier chez Str. cremoris (GARvie et MABBITT, I956) ou chez Lactobacillus casei (KIHARA et SNel, ig6o ; MCANeliy et Speck, I967 ; BaUdet et Cherbuliez, ig60). Cependant, nos résultats ne nous permettent pas encore de conclure si le pouvoir activateur de ces peptides serait bien dû au fait qu'ils agissent comme source d'acides aminés essentiels selon 1'hypothèse de TOKITA (Ig60) et McLEOD et GORDON (I96I).

Puisque plusieurs protéines (ribonucléase, lysozyme et glucagon) peuvent être hydrolysées par la protéase neutre en donnant des peptides stimulants, on peut penser que le pouvoir activateur n'est pas lié à une séquence précise d'acides aminés de ces peptides mais plutôt à un certain poids moléculaire, compris entre I ooo et I 500 , poids moléculaire des peptides stimulants fractionnés par chromatographie sur gel. Par contre, comme nous l'avons montré par bioautographie, tous les peptides de poids moléculaire compris entre I ooo et $\mathrm{I} 500$ ne sont pas stimulants. On peut donc en conclure que la composition en acides aminés de ces peptides est aussi un facteur important dans la stimulation des streptocoques thermophiles par les microcoques caséolytiques.

Enfin, il ne semble pas que la fraction glucidique de la caséine puisse jouer un rôle dans le phénomène d'activation puisque les peptides obtenus par action de la protéase sur des protéines ne contenant pas de fraction glucidique sont aussi stimulants. 


\section{REMERCIEMENTS}

Nous remercions vivement M. Ribadeau-Dumas du Laboratoire de Recherches sur les Protéines (C. N. R. Z.) de nous avoir procuré les caséines $\alpha_{s_{1}}$, $\beta$ - et $x$-purifiées.

Nos remerciements vont également à MM. Hermier et Auclair pour leurs suggestions et leurs critiques qui ont été pour nous une aide précieuse dans la réalisation de ce travail et la rédaction du manuscrit.

\section{SUMMARY}

\section{STIMULATION OF THERMOPHILIC LACTIC BACTERIA BY CASEOLYTIC MICROCOCCI \\ IDENTIFICATION AS PEPTIDES OF THE STIMUI,ATORY SUBSTANCES}

45 out of 306 isolated Micrococcus strains from various origins (udder milk samples; milk for cheese making ; milk serum and cheeses at various stages of production) were found to stimulate the activity of thermophilic streptococci.

These Micrococcus strains had a high caseolytic activity. The stimulatory substances were separated by gel filtration and identified as peptides.

The activity of thermophilic streptococci was alsos timulated by proteolysates of whole casein, $\alpha_{s_{1}}$-casein, $\beta$-casein, $x$-casein, ribonuclease and glucagon hydrolyzed by a neutral proteolytic enzyme obtained from a Micrococcus caseolytic strain.

The stimulatory effect seems to be due to peptides of $\mathbf{I} 000$ to I 500 molecular weight.

\section{RÉFÉRENCES BIBLIOGRAPHIQUES}

Baudet P., Cherbuliez E., ig6o. Strépogénines de la caséine. I. Étude de leur libération et de leur purification. Helvet. Chim. Acta., 43, g04-923.

Bencze W. L., Schmid K., I957. Determination of tyrosine and tryptophan in proteins, Anal. chem., 29, I $193-$ I 196.

Desmazeaud M., Hermier J., I968 a. Facteurs intervenant dans la production du système protéoIytique chez Micrococcus caseolyticus. Ann. Biol. anim. Bioch. Biophys., 8, 419-429.

Desmazeaud M., Hermier J., ig68 b. Isolement, purification et propriétés d'une protéase exocellulaire chez Micrococcus caseolyticus. Ann. Biol, anim. Bioch. Biophys., 8, 565-577.

Devoyod J.-J., I969. Filore microbienne du fromage de Roquefort. II. Staphylocoques et microcoques. Le Lait, 481-482, I-20.

FEIGL F., I956. Spot test in organic analysis., 5th ed. Elsevier Publishing Company, Amsterdam, p. 278.

Garvie L. I., MabBitT L. A., I956. Acid production in milk by starter cultures. The effect of peptone and other stimulatory substances. J. Dairy Res., 23, 305-314.

Guss M. L., Delwiche E. A., I954. Streptococcus thermophilus. J. Bacteriol., 67, 7I4-7I7.

Kinara H., SNell E. E., I960. Peptides and bacterial growth. VIII. The nature of strepogenin. J. Biol. Chem., 235, I409-I4I4.

Kunitz M., 1947. Crystalline soybean trypsin inhibitor. II. General properties. J. gen. Physiol., 30, $29 \mathrm{I}-3 \mathrm{IO}$.

MCANELLY J. K., SPECK M. L., I957. Amino acid content of a peptide stimulatory for Lactobacillus casei. J. Bacteriol., 73, 676-68I.

McLEod P., Gordon D. F. Jr., I96I. Peptides as sources of essential amino acids for lactic streptococci. J. Dairy Sci., 44, $237-242$.

De Man J.C., Rogosa M., Sharpe E., I960. A medium for the cultivation of Lactobacilli. J.appl. Bacteriol., 23, I30-I35.

Moore S., Strin W. H., 1954. A modified ninhydrin reagent for the photometric determination of amino acids and related compounds. J. Biol. Chem, 211, 907-9 3. 
Peppler M. J., I942. The heat resistance of mixed cultures of Streptococcus thermophilus and certain caseolytic bacteria. J. Bacteriol., 44, 389 .

Porath J., 1959. Fractionation of polypeptides and proteins on dextran gels. Clin. Chim. Acta., 4, 776-789.

Porath J., 1960. Gel filtration of proteins, peptides and amino acids. Biochim. Biophys. Acta., 49, 193-207.

RıtTer P., I959. Neue Erkenntnisse über die Gäranlage der Milch. Schweiz. Milchzeitung, 85, 60. Wissenschaftliche Beilage, 66, 521 .

Ritrer P., r962. Beeinflussung der Säuerung der im Emmentalerkäse notwendingen thermophilen Milchsäurebakterien durch fördernde Mikrokokken aus der Milch. XVI Internationaler Milchwirtschaftkongress B IV 2, 712-720.

Speck M. L., McANelly J. K., Wilbur J. D., 1958. Variability in response of lactic streptococci to stimulants in extracts of pancreas, liver and yeast. J. Dairy Sci., 41, 702-707.

Thomas S. B., Druce R. G., Peters G. I., Griffiths D. G., 1967. Incidence and significance of thermoduric bacteria in farm milk supplies. A reappraisal and review. J. appl. Bacteriol., 30, 265-298.

Tокіт F., I966. Peptides as amino acid sources for growth of lactic acid bacteria. Milchwissenschaft, 21, 220-222. 